\title{
$\int_{\text {(PSSR) }}$ Pakistan Social Sciences Review
}

RESEARCH PAPER

\section{Relationship between Emotional Intelligence and Teacher Effectiveness of Secondary School Teachers}

\author{
Dr. Muhammad Akram ${ }^{1}$ Dr. Farrukh Munir ${ }^{2}$ Samavia Zafar ${ }^{3}$
}

1. Associate Professor, Institute of Education and Research, University of the Punjab, Lahore, Punjab, Pakistan

2. Lecturer, Institute of Education and Research $\_$University of the Punjab, Lahore, Punjab, Pakistan

3. University of Education Lahore, Pakistan

\begin{tabular}{|c|c|}
\hline PAPER INFO & ABSTRACT \\
\hline Received: & This study was designed to measure the relationship between \\
\hline September 08, 2019 & emotional intelligence and teacher effectiveness. Emotional \\
\hline Accepted: & intelligence is an ability to monitor personal and others' emotions \\
\hline 25, 2019 & before taking some action or showing some behavior. Teacher \\
\hline Online: & effectiveness is a construct that measures how frequently teachers \\
\hline December 31, 2019 & $m$ certain roles based on some standards. It was a \\
\hline Keywords: & correlational study. Using multistage sampling technique, the \\
\hline Asses & researchers randomly selected 40 male and female high schools \\
\hline Emotional & (strata) in Okara district. Later, all 380 teachers of English and \\
\hline Intelligence & Mathematics in these schools were sampled for the $s$ \\
\hline Emotionality & Emotional Intelligence Questionnaire $(\mathrm{a}=.82)$ and School Self- \\
\hline $\begin{array}{l}\text { Sociability } \\
\text { Teacher }\end{array}$ & Assessment Instrument for Teacher Evaluation $(\alpha=.86)$ were used as \\
\hline Effectiveness, & $\begin{array}{l}\text { tools for data collection. Pearson correlation coefficient } \\
\text { demonstrated that emotional intelligence and teacher }\end{array}$ \\
\hline Teacher & effectiveness were strongly correlated with each other. Moreover, \\
\hline Evaluation & e teachers demonstrated better in emotional intelligence \\
\hline $\begin{array}{l}\text { Wellbeing; Self- } \\
\text { Control }\end{array}$ & \\
\hline $\begin{array}{l}\text { Corresponding } \\
\text { Author } \\
\text { akram.ier@pu.ed } \\
\text { u.pk }\end{array}$ & $\begin{array}{l}\text { recommended that female teachers may be given training to } \\
\text { teachers need to be more intelligence while demonstrating their } \\
\text { emotions. }\end{array}$ \\
\hline
\end{tabular}

\section{Introduction}

Emotional intelligence is the capability of individuals to recognize their own emotions and those of others, differentiate between different feelings and label them appropriately, use emotional information to guide thinking and behavior, and manage and/or adjust emotions to adapt to environments or achieve one's goal (Khokhar, \& Kush, 2009). The person who demonstrates higher level of emotional 
intelligence is hoped to perform his duty and roles better than the persons who demonstrate lower level of emotional intelligence (Rhee, \& White,2007). A plethora of research has demonstrated that teachers who have higher emotional intelligence perform better. They have better understanding of their own emotions, and they understand others' emotions accordingly. They do not lose their temper, demonstrate higher level of self-control, and focus on their wellbeing (Robbins \& Judge, 2009).

A plethora of research has revealed the relationship between emotional intelligence and effectiveness of teachers. Those with good emotional intelligence do not hesitate to take the opinion of others and then work on it to continue the development of its benefits (Ranjha \& Shujja, 2010). The teachers with the competences of emotional intelligence are optimist, adaptive, cooperative, trusting, authoritarian, open, accessible, and enthusiastic (Mortiboys, 2013). Having greater capacities of communication, a greater capacity for maintain relationships and the resolution of problems, a better momentum and the self-control and a good selfesteem with the significant level of motivation that are safer and more answerable and coping with stress (salami, 2010). This study pays attention to the teaching learning process and teacher's effectiveness will be rated by their students which is more reliable than principals and teachers themselves (Wilkinson, 2006).Teacher effectiveness is described as higher level of overall teacher performance that should frequently be performed by the teacher. The research tells that effective teachers play important role in maximizing student achievement and growth. Effective teachers are those who have deeper knowledge of the subjects they teacher, and they use different teaching methodologies to teach the students (Delvaux et al, 2013). They focus on developing their subject matter knowledge, use varying teaching strategies, assess their children through a variety of methods such as formative and summative assessment, and focus on improve classroom environment (Akram \& Zepeda, 2015).

Effective teaches are expected to use effective communication while they tech, and while they interact with parents and colleagues. In result, they earn good reputation and students' attention and students take more interest in their subjects and perform better(Peterson, 2004). In this research study, the researchers measured the relationship between emotional intelligence and teacher effectiveness. It is very important to conduct this study as some of the research studies in international scenario have provided evidence that these two variables are significantly positively correlated with each other (Rivers, Brackett, Reyes, Mayer, Caruso, \& Salovey, 2012). Effective teachers are the need of each school and student have right to learn from effective teachers. Similarly, the teachers who have self-control over their emotions and show positive mood, work harder than those teachers who lose their temper during teaching (Duncan-Andrade, 2007).

Based on these variables, the researchers conducted research to measure the relationship of emotional intelligence with teacher effectiveness on public school teachers in district Okara. Many researches have been conducted on measuring the 
relationship of emotional intelligence and teacher effectiveness in different countries (Allen \& Kaasalainen, 2012; Curci, Lanciano \& Soleti, 2014; Day \& Qing, 2009; Ghanizadeh, \& Moafian, 2010; Hassan, Jani, Som, Hamid, \& Azizam, 2015; Jha, \& Singh, 2012; Naqvi, Iqbl, \& Akhtar, 2016). However, the researchers have not been able to find studies that demonstrated the relationship between emotional intelligence and teacher effectiveness in public high schools in Pakistani context. The researchers used Emotional intelligence model of Petrides (2009) for measuring emotional intelligence of teachers employing professional standards for measuring teacher effectiveness.

The research tells that emotionally stable employees perform better than those who are less emotionally stable. Emotional intelligence is the ability to understand emotions and use those emotions for the wellbeing of the individuals. Similarly, teacher effectiveness is an important variable that ensures quality teaching which is birthright of every child. The research tells that effective teachers can maximize student performance (Akram, 2018; Akram \& Zepeda, 2015). It is observed in Pakistani school settings that many times teachers become more emotional while teaching and show less level of emotional stability that causes bad image, and perhaps lowers down their performance. Moreover, teacher quality has not been given importance in our educational setting; due to this teacher don't feel themselves accountable.

This study is an effort to fill the gap in literature; the result would lead conducting further studies in this area in future. This study will use teachers' perceptions of teacher effectiveness to correlate with emotional intelligence score of teachers as they perceived. This study will provide help to the educationists regarding the implications attached to the emotional intelligence and teacher effectiveness in public schools in Okara. This exploratory study in Pakistani context may establish social relationships and managing emotions in others (Salovey \& Mayer 1990). This study may help the government educational institutions to initiate some positive change in teaching as well (Kemp \& Hall, 1992).

\section{Conceptual Framework of the Study}

Conceptual framework is a set of interrelated concepts of the factors that show the relationships between the variables of the factors. Emotional intelligence includes 4 factors such as Wellbeing, Self-control, Emotionality, and Sociability, while teacher effectiveness includes 6 factors such as Subject matter knowledge, Instructional planning and strategies, Assessment, Learning environment, Effective communication, and Continuous Professional development of teachers. Based on these variables, the research assumes that the factors of emotional intelligence will significantly correlate with the factors of teacher effectiveness. 


\begin{tabular}{|l|l|}
\hline Emotional Intelligence & Teacher Effectiveness \\
Wellbeing & Subject Matter Knowledge \\
Self-control & Instructional Planning and Strategies \\
Emotionality & Assessment \\
& Learning Environment \\
& Effective Communication \\
& Continuous Professional \\
\hline
\end{tabular}

Figure 1: Conceptual Framework of the Study

\section{Literature Review}

Emotional intelligence appeared in the literature in 1990s when Goleman used this term in his research works. He said that emotional intelligence is more powerful than Intelligence Quotient and best predicts success of one in his life. Salovey and Mayer (1990) stated that emotional intelligence includes the ability to monitor feelings and emotions of own and other persons. Emotional intelligence is the ability to monitor and understand the emotions and how to regulate these emotions while dealing with other persons. So, in the common sense, we can say that it is an ability of teachers, in our research perspective, that shows how teachers understand their own and others' emotions while dealing with clients and stakeholder.

\section{Theories and Models of Emotional Intelligence}

Although many theories of EI have been established, there are three theories that have been utilized most frequently in empirical research on EI and are overwhelmingly the most widely known to the public (Mayer, 2006). The first is Mayer and Salovey's model of EI (1997). The second theory was the Emotional Quotient model of EI by Bar-On (1997) and the third one was Goldman's (1995) model of EI. Each theory defines and conceptualizes EI uniquely and each theory makes different predictions about emotionally intelligent individuals. The three major theories on EI are described below.

\section{The Mayer and Salovey Theory of EI}

Mayer and Salovey (1997) define EI as, "the set of abilities that account for how people's emotional perception and understanding vary in their accuracy". This theory divides EI abilities into four branches (Mayer, Salovey, \& Caruso, 2000). The first branch is 'perception and expression of emotion'. Examples of specific abilities in this branch are identifying and expressing one's own emotions and identifying and expressing the emotions of others. The second branch is 'assimilating emotion into thought'. Abilities in this branch include productively prioritizing thinking based on emotion and generating emotions that successfully aid in judgment and memory. 
The third branch is 'understanding and analyzing emotion'. Examples of abilities in this branch are successfully labeling complex emotions and their concurrent feelings as well as understanding relationships associated with shifts in emotions. The fourth branch is 'regulating emotion in self and others. Abilities in this branch include, but are not limited to, staying open to feelings, and monitoring and regulating emotions to stimulate emotional and intellectual growth. The authors of this model report that their theory of EI predicts that, like other intelligences, EI will meet three empirical criteria (Mayer et al., 2000). First, EI problems have right and wrong answers. Second, EI skills will correlate with other measures of mental ability. Third, EI ability level will increase with age. They also outline that their model of EI predicts certain characteristics of emotionally intelligent individuals; emotionally intelligent individuals are more likely to have experienced emotionally sensitive parenting, to choose appropriate emotional role models, to have lower levels of defensiveness, to develop expert knowledge in areas related to emotional knowledge, to be able to appropriately communicate and discuss their feelings, and to be able to successfully reframe emotions.

\section{Bar-On Emotional Quotient Theory and Model of EI}

Bar-On (1997) was pioneer of this concept. He said that EI is a series of noncognitive capabilities and skills that help the individual to cope with the challenges one must face during job performance. Bar-on stated that EI includes 5 major factors that have successfully been used as predictor of success of employees.

\section{Goldman's Theory of EI}

In this theory, Goleman has broken EI into five main areas: First, knowing one's emotions; second is managing emotions. The third area is 'motivating oneself' and is comprised of skills such as delaying gratification and resisting impulses. The fourth area is 'recognizing emotions in others' and encompasses such skills as empathy and understanding what others need or want. The fifth area is 'handling relationships' and includes skills such as successfully interacting with others and managing other emotions. Goldman (1995) claims that his model has strong predictively value towards individual success in his or her life.

\section{Petrides Model}

Petrides (2009) presented the model of EI and stated that EI is not abilitybased but it is based on emotional self-perceptions and emotional traits of the individual. This model comprises four factors namely: Wellbeing, Self-control, Emotionality, and Sociability. For this research study, the researchers has used Petrides model for getting teachers perceptions of emotional intelligence.

\section{Teacher Effectiveness}

Teacher effectiveness is a construct use for measuring the consistency of highest performance of teachers on teaching quality indicators (Polk, 2006). An 
effective teacher develops content clarity and pedagogical skills and good relationships with students (Hargreaves, 1998) and good communication skills (Akram, 2018). An effective is one who demonstrates sufficient knowledge of content matter, has deeper understanding of different teaching strategies, and knows about different assessment methods (Akram \& Zepeda, 2015). Effective teachers are assumed to create classroom environment that is conducive to learning.

\section{Teacher Evaluation Models}

The key research-based teacher evaluation models/frameworks include:

1. The TAP: Systems for Teacher and Student Achievement

2. Measures of Effective Teaching (MET) Model

3. Robert Marzano's Causal Teacher Evaluation Model

4. Charlotte Danielson's Framework for Teaching

5. Akram \& Zepeda Model of Teacher Evaluation

Each of these five models is briefly discussed with the contemporary research studies that have been conducted by different researchers.

\section{TAP: Systems for Teacher and Student Achievement.}

The TAP: System for Teachers and Student Achievement, launched in 1999 by Lowell Milken, focuses on identifying effective teachers through innovative and wide-ranging approaches. Arizona was the first state who implemented TAP in 2000-2001 (Hudson, 2010). The Teacher Advancement Program (TAP) involves four interrelated elements designed around teacher performance, teacher job satisfaction, recruitment, and retention in high schools (Daley \& Kim, 2010). The TAP system partly involves elements taken from Danielson's Framework for Teaching (1996).

\section{Measures of Effective Teaching Model}

The Bill and Melinda Gates Foundation aims to develop education facilities and opportunities along with dissemination of information technology facility. For this purpose, this organization also developed a teacher evaluation model named "Measures of Effective Teaching" (MET). This project focused on measuring teacher effectiveness on various factors such as teacher's knowledge, and their knowledge of professionalism.

\section{Robert Marzano's Causal Teacher Evaluation Model}

Robert Marzano developed a causal teacher evaluation model and applied this model to the schools in Florida, USA. He focused on using different teaching strategies and described that these strategies were causally linked to teacher effectiveness. Marzano's Causal Teacher Evaluation Model (2011) is a blend of research and theory correlate with student achievement across four domains: (a) 
Classroom strategies and behaviors, (b) Preparing and planning, (c) Reflecting on teaching, and (d) Collegiality and professionalism. This model has extensively been used in the United States for measuring teacher quality.

\section{Charlotte Danielson's Framework for Teaching (1996)}

This is one of the most widely used frameworks for teacher evaluation in the United States. It is a pedagogical model that assists the novice as well as experienced teachers to become effective and efficient teachers. The Framework for Teaching comprises 22 research- based components grouped into four domains of teaching responsibility: (a) Planning and Preparation, (b) Classroom Environment, (c) Instruction, and (d) Professional Responsibilities.

\section{Akram and Zepeda Model of Teacher Evaluation (2015)}

This teacher evaluation model was developed by Akram and Zepeda (2015) in Pakistani context. They authors used national professional standards for teachers to measure teacher effectiveness score. This model includes five factors: (a) Subject Matter Knowledge, (b) Instructional Planning and Strategies, (c) Assessment, (d) Learning Environment, and (e) Effective Communication. The detail is given below.

\section{Subject Matter Knowledge}

One of the significant variables that can affect student achievement is teacher's knowledge of the subject matter. Effective teachers are assumed to demonstrate concrete and correct knowledge of the subject. Akram (2018) stated that effective teachers have deeper understanding of the correct knowledge of their subject and they convey the content to the students with accuracy so that they do not get confused about the true knowledge. The subject matter knowledge includes content and pedagogical knowledge and focuses on how and what to teach (Shulman, 1986).

\section{Instructional Planning and Strategies}

Stronge (2010) stated that an effective teacher possesses knowledge of different teaching strategies and plans the instruction effectively. The Ministry of Education Pakistan (2009) keenly addressed this standard while documenting the professional standards for Pakistani teachers. Effective teachers know where to use which teaching method and how to involve all the students in their lesson (Tomlinson, 1999).

\section{Assessment}

Assessing students' performance is very important aspect of teaching and learning. Effective teachers know different types of assessments such as diagnostics, formative, and summative and their nature. They use varying assessment techniques and measure students' performance to ensure that teaching and learning processes are moving toward right directions. Teachers and students both analyze their 
performance and get feedback based on the assessment (Stronge, 2010; Akram 2018). Tomlinson (2007) suggested that teachers must choose the method of assessment that properly fits among students. High stakes testing, however, restricts teachers to formulate approaches of instruction (Stronge \& Xu, 2011).

\section{Learning Environment}

Learning environment is another useful aspect of teacher quality. If classroom environment is not friendly, students take classroom as a boring activity and they don't show their interest in the lesson. Consequently, they suffer a lot. Effective teachers are therefore supposed to development learning atmosphere where students take their teacher as a friend and mentor and a facilitator. Students openly ask questions to the teachers who respond them in proper way so that students do not feel ashamed and disrespected (Good \& Brophy, 1997; Marzano, Marzano, \& Pickering, 2003).

\section{Effective Communication}

Effective communication is required for ensuring good teaching. It is based on meaningful delivery of the subject matter knowledge. Peterson (2000) stated that effective communication is a two-way process where teachers listens actively students' problems and solves them accordingly. The communication is not limited to the students, but it also involves parents who are one of the important stakeholders of teaching and learning process. Body gestures are also included in communication.

\section{Continuous Professional Development}

Professional development is a process of improvement in teachers, knowledge and overall change in professional life. Effective teachers are assumed to be in touch with the latest knowledge of their subjects, practice new teaching methodologies, and adopt new and innovating methods of assessment (Akram, 2018). Effective teachers follow to professional standards and develop their knowledge accordingly (Stronge \& Tucker, 2003). The research indicated that good teachers care about their students resultantly, students respond to them by optimizing their commitment to learning (Lumpkin, 2007).

\section{Emotional Intelligence and Teacher Effectiveness}

The literature provides various evidences on measuring the relationship between these two variables. Hargreaves (2000) measured teachers' unhealthy relations with their students which bring negative influence on student. Another study of Singaravelu (2007) found that emotional intelligence of student teachers was above average as of emotional intelligence. Nasir and Iqbal (2012) conducted study on measuring the relationship of demographic factors with emotional intelligence of university students and found significant relationship between them. 
The study further explored that demographic variables predicted $19 \%$ of variance in emotional intelligence.In 2010, Ghanizadeh and Moafian investigated the relationship between 89 teachers' scores on EI and teacher effectiveness in Iran. Results indicated that there is a strong, positive relationship between overall teacher EI and teacher effectiveness. Further, results indicated that teacher EI can predict $15 \%$ of teacher effectiveness. Another study of Khodadady (2012) investigated the relationship between teacher EI and teacher effectiveness and found weak but significant negative relationship.

Jha and Singh (2012) investigated the relationship between emotional intelligence and teacher effectiveness of undergraduate faculty. The sample size was 250 faculty members from medical and engineering colleges in India. Participants completed the Emotional Intelligence Scale developed on Goldman' theory, and the used Teacher Effectiveness Scale to measure teacher effectiveness. Data analysis revealed a strong positive relationship between teacher EI and both measures of teacher effectiveness and that $42 \%$ of the variance in teacher effectiveness was predicted through their emotional intelligence. Various other studies found significant relationships between teachers' emotional intelligence and teacher effectiveness (Modupe, 2010).Chan (2004) conducted a study on 158 secondary school teachers to predict their self-efficacy through emotional intelligence. The findings of his study demonstrated emotional intelligence as a strong indicator of self-efficacy. Rastegar and Memarpour (2009) found emotional intelligence as a predictor of leadership abilities (Iordanoglou, 2007). The studies of Todd (2006), Drew (2006), Shahzad (2012), Naqvi, Iqbal and Akhtar (2016), Haq, Anwar, and Hassan (2017) found significant relationships between emotional intelligence and school effectiveness. The independent and dependent variable of this study. However, these studies were conducted in private schools or at university level. This study will be an addition to the body and knowledge and contribute to understand the relationship between emotional intelligence and teacher effectiveness more deeply.

\section{Material and Methods}

It was a correlational study based on survey method.All teachers in public boys' and girls' high schools in district Okara were the population of the study. Multiple techniques of sampling were used to collect data. Initially, 2 Tehsils(Depalpur and Okara) of district Okara were randomly selected as strata. Total number of schools in these two Tehsils was 120 . After that, 40 schools ( 20 boys and 20 girls) from each Tehsil were randomly selected. The researchers were able to access 380 teachers of English and mathematics of secondary classes.

\section{Instrumentation}

Two questionnaires were used for the proposed study. (1) The Emotional Intelligence Questionnaire-Short Form (TEIQue-SF)developed by Petrides (2009) and Self-assessment instrument for teacher Evaluation (SITE) of Akram and Zepeda (2015). Emotional Intelligence Questionnaire-Short Form (TEIQue-SF) of Petrides (2009) includes 
5 factors as: Wellbeing, Self-control, Emotionality, and Sociability. The scales of the items ranged from Strongly Disagree (1) to Strongly Agree (7) with seven points. It means that the teacher who selected 1 he demonstrated lowest score on psychological intelligence and the teacher who selected 7 demonstrated highest score on psychological intelligence.

Self-assessment instrument for teacher Evaluation (SITE) of Akram and Zepeda (2015) has been validated and tried out in Pakistan and found to be valid and reliable $(a=.92)$. It includes 6 factors namely: Subject matter knowledge, Instructional planning and strategies, Assessment, Learning Environment, Effective Communication, and Continuous Professional development. The scales of the questionnaire are as: Never (1), Rarely (2), Sometimes (3), Often (4), Always (5). The teacher who selected always will be considered more effective and the teacher who selected often against the item was considered as less effective teacher.

\section{Data Collection}

One of the researchers visited each sampled school, met with Headmaster/headmistress of the schools, and asked for his or her permission to collect data from teachers and students at their schools. Instead of taking consent from each student, head teachers' consent was used. Further, another consent form was used to get proper permission from each teacher of English and Mathematics. 380 teachers completed Emotional Intelligence Questionnaire (ETQ) and Self-assessment Instrument for teacher Evaluation (SITE). The researcher informed all teachers about the purpose of the study, gave ETQ and STEQ to them, and guided how to complete them. In this way, data were collected form 380 teachers. Each questionnaire was given a unique Identify number so that they could be used properly for data analysis.

\section{Data Entry and Cleaning}

The researchers used latest version of SPSS (20) for data analysis. All data were manually entered into SPSS. The frequencies tables showed minor mistakes in some of the entries. The researchers searched the relevant questionnaires and made corrections in the data file accordingly. The frequencies tables were run again and again to ensure the data were correctly entered and cleaned and ready for further analyses which are given in next chapter. After cleaning the data, the researchers calculated reliabilities of the factors. Table 1 shows details of the factor-wise and overall reliabilities.

Table 1

Factor-wise Reliabilities of Emotional Intelligence

\begin{tabular}{cc}
\hline Factor & $a$ \\
\hline Wellbeing & .72 \\
\hline Self-control & .75 \\
\hline
\end{tabular}




\begin{tabular}{ll}
\hline Emotionality & .71 \\
\hline Sociability & .76 \\
\hline Overall Reliability & .82 \\
\hline
\end{tabular}

Table 1 shows all factors of Emotional Intelligence demonstrated higher level of reliability. Overall reliability of the questionnaire was high (a.82), with factors realities as: wellbeing (a.72), Self-control (a.75), Emotionality (a.71), and Sociability (a.76). The table below demonstrates the overall and factor-wise reliability of teacher effectiveness scales.

Table 2

Factor-wise Reliabilities of Teacher Effectiveness

\begin{tabular}{ll}
\hline Factor & $\mathrm{a}$ \\
\hline Subject Matter knowledge & .72 \\
\hline Instructional Planning and Strategies & .75 \\
\hline Assessment & .71 \\
\hline Learning Environment & .76 \\
\hline Effective Communication & .78 \\
\hline Continuous Professional Development & .80 \\
\hline Overall Reliability & .86 \\
\hline
\end{tabular}

Table 2 shows that all factors were highly reliable. The overall reliability of the questionnaire was found to be high $(\alpha=.86)$ while factor-wise reliabilities were as under: Subject matter knowledge $(\alpha=.72)$, Instructional Planning and Strategies $(\alpha=.75)$, Assessment $(\alpha=.71)$, Learning Environment $(\alpha=.76), \quad$ Effective Communication $(\alpha=.78)$, and Continuous Professional Development $(\alpha=.80)$.

\section{Data Analysis}

The researchers have presented the analyzed data in various tables along with data interpretation. The relevant statistics have also been mentioned based on the research questions.

Table 3

Descriptive Analysis of Emotional Intelligence of Teachers (Factor-wise)

\begin{tabular}{|c|c|c|c|c|}
\hline Factors & Min & $\operatorname{Max}$ & Mean & $S D$ \\
\hline Wellbeing & 30.00 & 42.00 & 34.45 & 2.34 \\
\hline Self-control & 24.00 & 42.00 & 34.60 & 2.60 \\
\hline Emotionality & 36.00 & 56.00 & 35.90 & 2.50 \\
\hline Sociability & 30.00 & 42.00 & 34.84 & 2.94 \\
\hline Overall & 30.00 & 42.00 & 36.94 & 2.44 \\
\hline
\end{tabular}

According to Table 3, the minimum, the maximum, and the mean scores along with standard deviations were calculated. The results showed that teachers showed highest score on Emotionality $(M=35.90$, S.D. $=2.50)$ stated they were almost 
completely agreed that they showed emotional intelligence while responding to the students, parents and teachers followed by Sociability $(\mathrm{M}=34.84$, S.D. $=2.94)$. The lowest score was found on Wellbeing $(\mathrm{M}=34.45$, S.D. $=2.34)$. Overall, the mean items shows that teachers were almost completely agreed that they showed emotional intelligence while dealing with stakeholders.

Table 4

Descriptive Statistics on Teacher Effectiveness Scale

\begin{tabular}{|c|c|c|c|c|}
\hline Factor & Mir & $\operatorname{Max}$ & Mean & $S D$ \\
\hline Subject Matter Knowledge & 13.00 & 40.00 & 33.30 & 4.656 \\
\hline Instructional Planning and strategies & 7.00 & 60.00 & 21.14 & 4.274 \\
\hline Assessment & 5.00 & 56.00 & 15.53 & 3.407 \\
\hline Learning Environment & 9.00 & 25.00 & 21.17 & 3.807 \\
\hline Effective Communication & 3.00 & 15.00 & 13.18 & 2.343 \\
\hline Overall & 59.00 & 140.00 & 114.44 & 17.999 \\
\hline
\end{tabular}

Table 4 shows that the teachers rated themselves highest on subject matter knowledge, $(M=33.30$, S.D. $=4.656)$, followed by Instructional planning and strategies Effective communication $(\mathrm{M}=21.14$, S.D. $=4.274)$. The teachers rated lowest themselves on Assessment ( $M=15.53$, S.D.=3.407). The score on all factors showed that the teachers always or often demonstrated effectiveness while teaching.

Table 5

Factor-wise Correlation

\begin{tabular}{|c|c|c|c|c|c|}
\hline EI Factors & $S M K$ & IPES & $A$ & $L E$ & $E C$ \\
\hline Well-Being & $.45^{*}$ & $.67^{*}$ & $.62^{*}$ & $.58^{*}$ & $.66^{*}$ \\
\hline Self-Control & $.48^{*}$ & $.54^{*}$ & $.62^{*}$ & $.66^{*}$ & $.64^{*}$ \\
\hline Emotionality & $.62^{*}$ & $.48^{*}$ & $.64^{*}$ & $.68^{*}$ & $.52 *$ \\
\hline Sociability & $.64^{*}$ & $.44^{*}$ & $.64^{*}$ & $.54^{*}$ & $.66^{*}$ \\
\hline
\end{tabular}

$\left({ }^{*}=\right.$ 2-tailed Sig $\left.=.05\right)$

Table 5 presents the results of relationship between the factors of emotional intelligence and teacher effectiveness. The highest relationship was found between Emotionality and Learning environment $(\mathrm{r}=.68)$, followed by wellbeing and instructional planning and strategies $(\mathrm{r}=.66)$, instructional planning and effective communication $(\mathrm{r}=.66)$ and sociability and effective communication. The lowest relationship was fund between Sociability and instructional planning and strategies $(\mathrm{r}=.44)$. In overall, the significant moderate relationships were found between all the factors of emotional intelligence and teacher effectiveness. 
Table 6

Pearson Correlation Coefficient between Emotional Intelligence and Teacher Effectiveness

Teacher Effectiveness ( $\mathrm{r}$ )

Emotional Intelligence .722

Overall relationship between emotional intelligence and teacher effectiveness was also calculated. According to Table 6, a strong significant positive correlation between Emotional intelligence of teachers and Teacher Effectiveness score $(r=.722)$ was found. Positive relationship means that when the value or score on one variable increased, the score on the second variable also increased.

Table 7

T-test for Independent samples-Comparing Emotional Effectiveness

\begin{tabular}{|c|c|c|c|c|c|c|c|}
\hline Factors & Gender & $N$ & Mean & S.D. & $t$ & $d f$ & Sig. \\
\hline \multirow{2}{*}{ Wellbeing } & Male & 170 & 32.886 & 4.671 & \multirow{2}{*}{.191} & \multirow{2}{*}{378} & \multirow{2}{*}{.030} \\
\hline & Female & 210 & 34.793 & 4.849 & & & \\
\hline \multirow{2}{*}{ Self-control } & Male & 170 & 35.969 & 5.640 & \multirow{2}{*}{.276} & \multirow{2}{*}{378} & \multirow{2}{*}{.020} \\
\hline & Female & 210 & 37.798 & 6.241 & & & \\
\hline \multirow{2}{*}{ Emotionality } & Male & 170 & 37.234 & 7.971 & \multirow{2}{*}{.480} & \multirow{2}{*}{378} & \multirow{2}{*}{.001} \\
\hline & Female & 210 & 39.896 & 6.536 & & & \\
\hline \multirow{2}{*}{ Sociability } & Male & 170 & 34.280 & 3.370 & \multirow{2}{*}{.320} & \multirow{2}{*}{378} & \multirow{2}{*}{.014} \\
\hline & Female & 210 & 36.771 & 3.766 & & & \\
\hline \multirow{2}{*}{ Overall EI } & Male & 170 & 37.537 & 4.196 & \multirow{2}{*}{.524} & \multirow{2}{*}{378} & \multirow{2}{*}{.000} \\
\hline & Female & 210 & 37.782 & 4.746 & & & \\
\hline
\end{tabular}

The t-test for independent samples was run to measure the difference in teachers' perceptions of emotional intelligence based on their gender. According to Table 5, significant differences were found between male and female teachers perceptions of emotional intelligence. Female teachers demonstrated higher score on all factors than male teachers and statistically significantly differed on the factors such as wellbeing $\mathrm{t}(378)=.191, \mathrm{p} 0.05$, self-control $\mathrm{t}(378)=.276$, p 0.05 , emotionality $\mathrm{t}(378)=.480$, p 0.05 , and sociability $\mathrm{t}(378)=.320$, p 0.05 . The overall results showed that female teachers significantly showed higher emotional intelligence than male teachers. $\mathrm{t}(378)=.524, \mathrm{p} 0.05$. 
Table 8

Independent Samples t-test for Comparing Teacher Effectiveness

\begin{tabular}{|c|c|c|c|c|c|c|c|}
\hline Factors & Gender & $N$ & Mean & $S D$ & $t$ & $d f$ & Sig. \\
\hline \multirow{2}{*}{$\begin{array}{l}\text { Subject matter } \\
\text { knowledge }\end{array}$} & Male & 170 & 33.13 & 5.371 & \multirow{2}{*}{1.976} & \multirow{2}{*}{2068} & \multirow{2}{*}{.002} \\
\hline & Female & 210 & 31.00 & 5.732 & & & \\
\hline \multirow{2}{*}{$\begin{array}{l}\text { Instructional Planning } \\
\text { and Strategies }\end{array}$} & Male & 170 & 21.03 & 4.911 & \multirow{2}{*}{-.293} & \multirow{2}{*}{2068} & \multirow{2}{*}{.001} \\
\hline & Female & 210 & 20.18 & 5.405 & & & \\
\hline \multirow{2}{*}{ Assessment } & Male & 170 & 15.71 & 4.692 & \multirow{2}{*}{1.058} & \multirow{2}{*}{2068} & \multirow{2}{*}{.001} \\
\hline & Female & 210 & 14.22 & 4.572 & & & \\
\hline \multirow{2}{*}{ Learning Environment } & Male & 170 & 21.86 & 3.349 & \multirow{2}{*}{2.452} & \multirow{2}{*}{2068} & \multirow{2}{*}{.000} \\
\hline & Female & 210 & 19.92 & 3.932 & & & \\
\hline \multirow{2}{*}{$\begin{array}{c}\text { Effective } \\
\text { Communication }\end{array}$} & Male & 170 & 14.46 & 2.256 & \multirow{2}{*}{1.647} & \multirow{2}{*}{2068} & \multirow{2}{*}{.021} \\
\hline & Female & 210 & 13.07 & 2.368 & & & \\
\hline \multirow{2}{*}{ Overall } & Male & 170 & 124.12 & 17.202 & \multirow{2}{*}{2.011} & \multirow{2}{*}{2068} & \multirow{2}{*}{.000} \\
\hline & Female & 210 & 110.46 & 18.203 & & & \\
\hline
\end{tabular}

The independent samples t-test was run to compare teacher effectiveness score of male and female teachers based on teachers' perceptions. The results showed that male teachers demonstrated higher score on all factors of teacher effectiveness as compared to female teachers, subject matter knowledge, $t(2068)$ $=1.976, \mathrm{p} 0.05$, instructional planning and strategy, $t(2068)=-.293, \mathrm{p} 0.05$, assessment, $t(2068)=1.058, \mathrm{p} 0.05$, learning environment, $t(2068)=2.452, \mathrm{p} 0.05$, and effective communication, $t(2068)=1.647$, p 0.05 with overall score as $t(2068)=2.011$, $\mathrm{p}$ 0.05. The results showed that male teachers significantly differently rated themselves as more effectiveness as compared to female teachers.

\section{Conclusion}

The study found significant relationship between emotional intelligence and teacher effectiveness that lead to the linking these variables for future educational improvement. Singh and Jha (2012) found significant relationship between emotional intelligence and teacher effectiveness in medical and engineering faculty members. The results of the study conducted by Adeyemo and Chukwudi (2014) teacher emotional intelligence as predictor of teacher effectiveness in Nigerian universities. Similar results were found in various other studies (Asrar-ul-Haq, Anwar, \& Hassan, 2017; Penrose, Perry, \& Ball, 2007). Emotional intelligence, therefore, can be considered a strong predictor of teacher effectiveness.

\section{Recommendations}

1. The study found strong correlation between emotional intelligence and teacher effectiveness of secondary school teachers. Further studies should be conducted to find out the reasons of such relationships with larger sample size. Qualitative research may be conducted on exploring further. 
2. The study found that female teachers performed better on emotional intelligence scale that male teachers. Trainings can be conducted for male teachers on how to be more intelligent regarding their feelings and emotions while dealing with stakeholders such as students.

3. Male teachers showed higher score on teacher effectiveness scales that female teachers. Female teachers should be introduced with awareness sessions and training on maximizing their teaching effectiveness on national professional standards. 


\section{References}

Adeyemo, D. A., \& Chukwudi, A. R. (2014). Emotional Intelligence and Teacher Efficacy as Predictors of Teacher Effectiveness among Pre-Service Teachers in Some Nigerian Universities. International Journal of Evaluation and research in Education, 3(2), 85-90.

Akram, M., \& Zepeda, S. J. (2015). Development and validation of teacher selfassessment instrument. Journal of Research and Reflections in Education,9(2), 134148.

Allen, D., Ploeg, J., \& Kaasalainen, S. (2012). The relationship between emotional intelligence and clinical teaching effectiveness in nursing faculty. Journal of Professional Nursing, 28(4), 231-240.

Asrar-ul-Haq, M., Anwar, S., \& Hassan, M. (2017). Impact of emotional intelligence on teacher $\mathrm{s}$ performance in higher education institutions of Pakistan. Future Business Journal, 3(2), 87-97.

Bar-On, R. (1997). The Emotional Intelligence Inventory (EQ-i): Technical manual. Toronto: Multi-Health Systems.

Curci, A., Lanciano, T., \& Soleti, E. (2014). Emotions in the classroom: The role of teachers' emotional intelligence ability in predicting students' achievement. American Journal of Psychology, 127(4), 431-445.

Day, C. \& Qing, G. (2009). Teacher emotions: Wellbeing and effectiveness. In P.A. Schutz \& M. Zembylas (Eds.), Advances in Teacher Emotion Research: The Impact on Teacher's Lives. New York: Springer.

Delvaux, E., Vanhoof, J., Tuytens, M., Vekeman, E., Devos, G., \& Van Petegem, P. (2013). How may teacher evaluation have an impact on professional development? A multilevel analysis. Teaching and Teacher Education,3(6), 1-11.

Duncan-Andrade, J. (2007). Gangstas, wankstas, and ridas: Defining, developing, and supporting effective teachers in urban schools. International Journal of Qualitative Studies in Education,20(6), 617-638.

Ghanizadeh, A., \& Moafian, F. (2010). The role of EFL teachers' emotional intelligence in their success. ELT Journal: English Language Teachers Journal, 64(4), 424-435.

Goldman, D. (1995). Emotional intelligence. New York, NY: Bantam.

Goleman, D. (1995). Emotional intelligence: Why it can matter more than IQ. New York. 
Hargreaves, A. (1998). The emotional practice of teaching. Teaching and Teacher Education, 14, (8), 835-854.

Hassan, N, Jani, S. H. M., Som, R. M, Hamid, N.Z. A., \& Azizam, N. A. (2015). The Relationship between Emotional Intelligence and Teaching Effectiveness among Lecturers at University Technology MARA, Puncak Alam, Malaysia.

Jha, A., \& Singh, I. (2012). Teacher effectiveness in relation to emotional intelligence among medical and engineering faculty members. Europe's Journal of Psychology,8(4), 667-685.

Kemp, L., \& Hall, A. H. (1992). Impact of effective teaching research on student achievement and teacher performance: Equity and access implications for quality education. Jackson, MS: Jackson State University. (ERIC Document Reproduction Services No. ED348360).

Khokhar, C. P., \& Kush, T. (2009). Emotional intelligence and work performance among executives. Europe's Journal of Psychology,5(1), 1-11.

Mayer, J.D. (2006). A new field guide to emotional intelligence. In J. Ciarrochi, J. P. Forgas, \& J.D. Mayer (Eds.), Emotional intelligence in everyday life (2nd ed., pp. 326). New York, NY: Psychology Press.

Mayer, J.D., \& Salovey, P. (1997). What is emotional intelligence? In P.Salovey \& D. Sluyter (Eds.) Emotional development and emotional intelligence: Implications for educators (pp.3-31). New York: Basic Books.

Mayer, J.D., Salovey, P., \& Caruso, D.R. (2000). Emotional intelligence as zeitgeist, as personality and as a mental ability. In R. Bar-On and J. Parker (Eds), The Handbook of emotional intelligence: Theory, development, assessment and application at home, school and in the workplace. (pp.92-117). San Francisco, California: Josey-Bass Inc.

Mayer, J.D., Salovey, P., \& Caruso, D.R. (2000). Models of emotional intelligence. In R. J. Sternberg (Ed.). Handbook of Intelligence (pp. 396-420). Cambridge, England: Cambridge University Press.

Mortiboys, A. (2013). Teaching with emotional intelligence: A step-by-step guide for higher and further education professionals. Routledge.

Naqvi, I. H., Iqbl, M., Akhtar, S. N. (2016). The relationship between emotional intelligence and performance of secondary school teachers. Bulletin of Education and Research, 38(1), 209-224.

Penrose, A., Perry, C., \& Ball, I. (2007). Emotional intelligence and teacher selfefficacy: The contribution of teacher status and length of experience. Issues in educational research, 17(1), 107-126. 
Peterson, K. (2004). Research on schoolteacher evaluation. NASSP Bulletin, 88(639), 60-79.

Petrides, K. V. (2009). Psychometric properties of the TraitEmotional Intelligence Questionnaire. In C. Stough, D. H. Saklofske, and J. D. Parker, Advances in theassessment of emotional intelligence. New York: Springer. DOI: 10.1007/978-0387-88370-0_5

Polk, J. A. (2006). Traits of effective teachers. Arts Education Policy Review, 107, 23-30.

Ranjha, A. Y. \& Shujja, S. (2010). Emotional intelligence and psychological adjustment of nurses serving in emergency and non-emergency wards. Journal of Behavioural Sciences,20(2), 150-155.

Rhee, K. S., \& White, R. J. (2007). The emotional intelligence of entrepreneurs. Journal of Small Business \& Entrepreneurship,20(4),409-425.

Rivers, S. E., Brackett, M. A., Reyes, M. R., Mayer, J. D., Caruso, D. R., \& Salovey, P. (2012). Measuring emotional intelligence in early adolescence with the MSCEITYV: Psychometric properties and relationship with academic performance and psychosocial functioning. Journal of Psychoeducational Assessment, 30(4), 344-366.

Robbins, S.P., \& Judge, T. A. (2009). Essentials of Organizational Behavior (10th Edition). Upper Saddle River, NJ: Prentice Hall.

Salami, S. O. (2010). Emotional intelligence, self-efficacy, psychological well-being and students' attitudes: Implications for quality education. European Journal of Educational Studies, 2(3), 247-257.

Salovey, P., \& Mayer, J. D. (1990). Emotional intelligence. Imagination, Cognition and Personality, 9(3), 185-211.

Singh, I., \& Jha, A. (2012). Teacher effectiveness in relation to emotional intelligence among medical and engineering faculty members. Europe's Journal of Psychology, 8(4), 667-685.

Wilkinson, L. A. (2006). Conjoint behavioral consultation: An emerging and effective model for developing home-school partnerships. International journal of behavioral consultation and therapy,2(2), 224-237. 